\title{
FOUCAULT E O NEOLIBERALISMO DE SUBJETIVIDADES PRECÁRIAS: INCIDÊNCIAS NA ESCOLA PÚBLICA BRASILEIRA
}

Alexandre Filordi de Carvalho

\begin{abstract}
Resumo: O artigo investiga como o neoliberalismo é uma arte contemporânea de produzir e de governar subjetividades precárias. A hipótese é a de que a arte de governar neoliberal, ao compor o que Foucault denominou de dispositivo de segurança, atua diretamente precarizando a escola pública. $\mathrm{O}$ intuito dessa ação é o de fazer da potência subjetiva matéria de adaptação para a precarização. Logo, a escola pública precarizada funcionaria como instituição que adéqua seus sujeitos às demandas neoliberais precarizadoras. $\mathrm{O}$ artigo usa dados econômicos para poder comprovar tal perspectiva. Ao cabo, o artigo defende ser urgente a escola pública recobrar a função de educar contra a precarização, afirmando-se como espaço público, laico e gratuito de formação para a denúncia e a resistência à arte de governo neoliberal.
\end{abstract}

Palavras chave: Neoliberalismo; Escola pública; Subjetividades; Precarização; Foucault

\section{FOUCAULT AND THE NEOLIBERALISM OF PRECARIOUS SUBJECTIVITIES: INCIDENCES IN THE BRAZILIAN PUBLIC SCHOOL}

\begin{abstract}
The article investigates how neoliberalism is a contemporary art of producing and governing precarious subjectivities. The hypothesis is that the neoliberal art of governing, when composing what Foucault called a security dispositive, acts straight away to the public school. The purpose of this action is to make subjective power a issue of adaptation for precariousness. Therefore, the precarious public school would function as an institution that adapts its subjects to the precarious neoliberal demands. The article uses economic data to prove this perspective. After all, the article argues that it is urgent for the public school recovering the function of educating against precariousness, asserting itself as a public, secular and free training space for denouncing and resisting the art of neoliberal government.
\end{abstract}

Key words: Neoliberalism; Public School; Subjectivities; Precariousness; Foucault

\section{Introdução a uma problematização urgente}

As pesquisas abordando o alcance planetário e a complexidade da temática neoliberal se atualizam incansavelmente (ANTUNES, 2018; BERARDI, 2005; BOEVER; NEIDICH, 2013; BUTLER, 2019; BROWN, 2019; CORTINA, 2017; KLEIN, 2007; LAZARATTO, 2014; 2019). De modo geral, suas análises convergem causas e consequências.

No âmbito das causas, prevalece-se o rentismo sobreposto como atualização exploratória e desigual do capitalismo circular no planeta, conforme os interesses de um estamento social plutocrático. (KLEIN, 2007; HOSANG; LOWDENS, 2019; MAYER, 2017). Já uma das consequências reinantes é a educação pública tomada por objeto de "cuidado" e "atenção" do governamento neoliberal. 
O que salta aos olhos nessa conjuntura são as estratégias de formação humana situadas e articuladas como alvo a ser estabelecido sob um currículo global. A Organização para a Cooperação e o Desenvolvimento Econômico (OCDE), nesse sentido, se vale do PISA (Programme for International Student Assessment), do qual o Brasil se submete, justamente para atuar planificando quatro competências a ditar as estratégias educacionais: conhecimentos, valores, atitudes e habilidades, desde que ao serviço do desenvolvimento econômico.

Os países desenvolvidos economicamente, entretanto, são mantidos por uma política endógena protecionista produzida, sustentada e divulgada sob a rubrica dos interesses daqueles que, conforme denominou Mayer (2017, p. 217), financiam a "infraestrutura política subterrânea”. Trata-se das pessoas mais ricas do planeta, por sua vez, mantenedoras das conexões políticas de extrema-direita, recobertas pela tintura doutrinária da liberdade, das defesas da propriedade privada e da livre iniciativa concorrencial, além da propalada defesa da vida (LEVITSKY; ZIBLAT, 2018; MAYER, 2017; ROSE; 2011). Percebendo com precisão esse movimento, Rose (2011, p. 231) alerta: “O neoliberalismo é talvez de duradoura significância, e não apenas um fenômeno efêmero e corrupto, uma vez que foi a direita, e não a esquerda, que teve o sucesso em formular uma racionalidade política consoante com o novo regime do self', leia-se, regime de produção de sujeitos adaptados à tal racionalidade política.

Embora não componha parte dos objetivos deste artigo tratar do personalismo do neoliberalismo, no entanto, busca-se evidenciar que o neoliberalismo atual funciona como arte de governar e que, para tanto, lança mão de estratégias de formações subjetivas devotadas à manutenção do próprio sistema neoliberal de governo. Como será mostrado, é o dispositivo de segurança (FOUCAULT, 2004 b) o responsável por fazer o neoliberalismo funcionar como arte de governo a ele protetiva.

O objetivo deste artigo é o de evidenciar como o neoliberalismo é uma arte contemporânea de produzir e de governar subjetividades precárias. A precariedade encontra-se no âmbito da formação de componentes subjetivos (CARVALHO; GALLO, 2019; LAZZARATO, 2019; ROSE, 2011) responsáveis por funcionar como respostas positivas adaptativas à adequação das demandas neoliberais de precarização existencial (ANTUNES, 2018; HOSANG; LOWDENS, 2019; LAVAL, 2019). Daí a educação como chave indispensável a esse processo. E mais, daí as razões pelas quais a escola pública precisa ser precarizada, pois ela passa a funcionar como laboratório condicionante à própria precarização.

A concepção que Foucault (2004 a) destinou para o neoliberalismo norte-americano em $O$ nascimento da biopolítica será privilegiada, pois como se sabe (ANTUNES, 2018; KINZER, 2006; STEGER; ROY, 2010), após os anos de 1980 foi a vertente norte-americana que prevaleceu como matriz político-neoliberal mundial. (LAZZARATO, 2019; KINZER, 2006; KLEIN, 2007; STEGER; ROY, 2010). Não obstante, também foi a partir deste neoliberalismo que se difundiu a perspectiva de política educacional global sob os dogmas do capital humano. Este, por sua vez, entabulado como competência atrelada ao 
autoempreendedorismo de si mesmo, ao princípio do aprender a aprender e à autoexploração subjetiva como capital negociável. Mas a essa altura, o capital humano (BECKER, 1984; FRIEDMAN 1955; SCHULTZ, 1961) passou a ser a porta de entrada da justificativa do atomismo individual pela virtude do egoísmo, por extensão, condizente com a fragilização das redes de proteção coletivas outrora presentes no tecido social (STANDING, 2017).

Na primeira parte, o artigo investiga a concepção foucaultiana que permite compreender o alcance atual desse neoliberalismo. A hipótese fundamental é a de que o neoliberalismo é componente primordial do dispositivo de segurança. Na segunda etapa, buscar-se-á colocar em questão a relação da emersão do precariado como plataforma de adaptação à arte de governar neoliberal, além de suas consequências. Uma série de dados serão aportados nessa conjuntura, identificando o impacto da precarização da escola pública.

Ao cabo, o artigo emerge as conclusões seguintes. É urgente que a escola pública recobre a função de educar contra a precarização, afirmando-se como espaço público, laico e gratuito de formação para a denúncia e a resistência à arte de governo neoliberal.

\section{Neoliberalismo como arte de produzir e de governar subjetividades precárias}

No curso Nascimento da Biopolítica, Foucault (2004 a, p. 224) argumenta: “o liberalismo, na América, é uma maneira inteira de ser e de pensar". Tal afirmação é expressão sintética do impacto do liberalismo, em primeiro lugar, como princípio teórico muito bem agenciado e fundamentado, concernente aos princípios implicados em suas práticas. Em segundo lugar, indica a substancial consequência nos modos precisos pelos quais o liberalismo estadunidense imprimiu, por intermédio da defesa das verdades sustentadas em seus ideários, uma praxeologia, ou seja, objetivou a conduta, o comportamento e ação de seus sujeitos. Von Mises (2010), indicou que o liberalismo é doutrina política aplicada aos problemas suscitados pela ação humana na sociedade, uma praxeologia, "visando a ajustar os indivíduos às condições do meio ambiente onde o ser em questão deseja subsistir" (VON MISES, 2010, s/p).

Mas como se dá a passagem do liberalismo como maneira global de pensar e de ser para o neoliberalismo? É fato que o neoliberalismo, tal como se difundiu e se consolidou a partir dos anos de 1980 no planeta, (KINZER; 2006; KLEIN, 2007; KINZER; STEGER; ROY, 2010) não passa de uma oclusão política contrária a toda perspectiva que pudesse considerar o Estado como agente sócio-político investidor e garantidor de regras estáveis no âmbito socioeconômico. Em outros termos, por intermédio do tatcherismo e do reaganismo, lançaram-se as bases para a teoria e a praxeologia neoliberal cuja centralidade política se pautava pela desidratação do papel do Estado como agente atuante no âmbito do bem-estar social. No 
entanto, o neoliberalismo se firmou sob a batuta da influência dos consórcios oligárquicos e plutocráticos norte-americanos (Mayer, 2017), espécie de interventor global, maximizando um duplo interesse.

Em primeiro lugar, "no neoliberalismo norte-americano trata-se exclusivamente de generalizar a forma econômica do mercado. Trata-se de generalizá-la em todo o corpo social e generalizá-la inclusive em todo o sistema social que, de ordinário, não passa ou não é sancionado senão por trocas monetárias" (FOUCAULT, 2004 a, p. 248). Com efeito, uma perspectiva monetária inteira, a partir de então, ditada pelo Banco Mundial, Fundo Monetário Internacional (FMI), Banco Interamericano de Desenvolvimento (BID), Organização Mundial do Comércio (OMC), Organização para a Cooperação e Desenvolvimento Econômico (OCDE), dentre outras, mas todas arrimadas e controladas pelos E.U.A, açambarcaram majoritariamente a governança monetária no planeta.

O eixo do monetarismo neoliberal, contudo, e em segundo lugar, teve por operador a mão invisível da oligarquia norte-americana. Nos termos de Mayer (2017, p. 14), “as oligárquicas na América não ditam as regras diretamente, em vez disso, no entanto, usam suas fortunas para produzir resultados políticos que favoreçam seus interesses". O idílio da proteção à vida, da prosperidade e da liberdade individual neoliberais, maturados conforme a sustentação de um submundo teórico neoliberal, desembocou na atualidade exploratória da precarização (ANTUNES, 2018; STANDING, 2017), pois a precarização assume o contorno da exploração maximizada pelos lucros.

Ao situar as pesquisas de Foucault acerca do neoliberalismo em Nascimento da Biopolítica, empreendidas em 1978-1979, no lastro das investigações acerca dos dispositivos de segurança, sistematizadas no curso Segurança, Território, População de 1977-1978, um cenário problematizador, e de longo alcance, emerge. Se o dispositivo de segurança (FOUCAULT, 2004 b) diz respeito às formas pelas quais as tecnologias de poder se voltaram para a produção e a gestão de populações inteiras, sempre por intermédio da especialização das artes de governar, fazendo funcionar no interior de suas estratégias elementos jurídicos, normativos, administrativos, todos eles, eficientes em termos de custos, pode-se dizer que o neoliberalismo é parte majoritária da composição do dispositivo de segurança.

Em primeiro lugar, porque o dispositivo de segurança opera no registro das forças centrífugas, ou seja, ampliando o seu alcance no tecido social. Assim, o dispositivo de segurança que faz funcionar o neoliberalismo, ironicamente "em defesa da sociedade",ii, não deixa escapar nenhum aspecto da vida que possa redundar em exploração mercadológica, rentista e lucrativa. Por conseguinte, o dispositivo de segurança "agrega sem cessar novos elementos, integra-se a produção, a psicologia, os comportamentos, as maneiras de fazer dos produtores, dos compradores, dos consumidores, dos importadores, dos exportadores, compondo-se o mercado mundial" (FOUCAULT, 2004 b, p. 46). Nesse sentido, o neoliberalismo atua difundindo a lógica do mercado. Assim como o mercado não pode nunca perder, o neoliberalismo assume a tecnologia do dispositivo de segurança que tende a proteger os vencedores em detrimento dos vencidos. 
A partir daí, o neoliberalismo é menos uma política de Estado mínimo e mais uma política de intervenção global tendenciosa no Estado, fazendo-o inclinar-se aos dispositivos de segurança que uma elite econômica maneja para que o Estado sustente leis e procedimentos legais que impeçam a organização social dos trabalhadores; favoreça os canais de endividamento público com o setor privado; estimule o financiamento da educação superior privada; diminua os investimentos públicos em seguridade social, deslocando-os para a especulação financeira. Seja como for, trata-se da "total concentração da elite política e corporativa em nome da segurança, com o Estado desempenhando o papel de guia nos negócios, bem como o de maior provedor de oportunidades para potencializá-los, graças ao fornecimento de contratos econômicos" (KLEIN, 2007, p. 399).

Em suma, nessa perspectiva, o neoliberalismo compõe o dispositivo de segurança porque ele está associado a uma plutocracia que "defende" a população dos pretensos erros do Estado. Entretanto, o faz cinicamente, pois é parasitando-o e vampirizando-o que ela desloca os seus interesses para o Estado. Ao cabo, conforme a precisa interpretação de Berardi (2005, p. 126), o neoliberalismo "reformula as teses nesse sentido: na evolução natural, o mais forte prevalece, e essa é a melhor coisa que pode acontecer, porque assim se exercita uma seleção que leva ao aprimoramento das espécies animais".

Em segundo lugar, todavia, o neoliberalismo integra o dispositivo de segurança porque reativa o princípio de que a política é a continuação da guerra por outros meios (FOUCAULT, 2002), no sentido bem preciso de que defenderá os seus interesses com o regime de verdade e as tecnologias políticas a ele propício. O mobilizador de eficiência concreta e vital do neoliberalismo, então, passa a ser a sujeição da vida aos coeficientes políticos dos princípios e das práticas pelos quais ele milita. É nessa direção que se pode compreender os termos de Laval (2019, p. 47): “as sociedades de mercado se caracterizam pela sujeição de todas as atividades à lógica da valorização do capital, considerada evidente, inevitável, imperativa, da qual nenhum ser racional pode esquivar-se".

Duas consequências desprendem-se de modo inevitável do caráter beligerante do neoliberalismo. De um lado, como bem assinalou Lazzarato (2019, p. 24), o neoliberalismo jamais se envergonhou de se associar aos fascistas, torturadores e criminosos: "coisas que os liberais (neo ou não) estão sempre dispostos a fazer e a refazer se em algum momento a 'propriedade privada' é ameaçada, ainda que virtualmente". O lawfare ocupa papel relevante nessa etapa. Trata-se de manobras jurídico-legais, usadas como plataforma bélica cujos objetivos alcançam compensações econômicas aos detentores da política neoliberal no dispositivo de segurança. Nesse caso, pouco importam as das tensões internas e externas causadas à soberania dos Estadosiii. O uso securitário da lei, nesse aspecto, coaduna-se com a extensão operativa do neoliberalismo, ou seja, o sistema jurídico ocupa lugar-tenente na defesa de interesses escusos. Por exemplo, antes mesmo de uma política ao modo do Patriot Act, pós-atentado de 11 de setembro de 2001, demandante de ações antidemocráticas no âmbito mundial, o neoliberalismo norte-americano havia elegido 
o século XX como sendo o century of America. O século da América, como analisou Kinzer (2006, p. 302) justificava que "os americanos tinham o direito e até a obrigação de depor regimes considerados mal por eles", ainda que fosse um inimigo interno.

Considerando o century of América, Lazzarato (2019, p. 21) acerta no diagnóstico da violência do neoliberalismo embora, talvez, carregando equivocadamente na tinta ao criticar Foucault:

A tradição iniciada por Michel Foucault de analisar o neoliberalismo ignorando completamente a genealogia turva, escabrosa e violenta, em que se cruzam torturadores militares e criminosos da teoria econômica, foi catastrófica sob diversos pontos de vista. O problema não é "moral" (a indignação com o esmagamento armado dos processos revolucionários na América Latina), mas antes de tudo teórico e político.

O exagero se assenta no fato de Lazzarato ignorar que a análise de Foucault não está isolada, como venho sustendo, do dispositivo de segurança. $\mathrm{O}$ dispositivo de segurança pressupõe a violência, pois para regular, regulamentar e administrar em âmbito populacional é preciso, como evidenciou Foucault (2002; 2004 a 2004 b) estabelecer um regime de verdade coextensivo a uma arte de governar, isto é, aos modos racionalizados de se estruturar o comportamento das pessoas.

Como todo regime de verdade é a disposição de uma veridicção, ou seja, a divisão do que é considerado verdadeiro ou falso (FOUCAULT, 2004 a), o neoliberalismo já parte da violência de seu regime de verdade. Tal violência, sob a conjuntura maior do dispositivo de segurança, justificada teoricamente, dissipa pelos microdispositivos institucionais pertinentes ao neoliberalismo sua própria veridicção. Em outros termos, há de se indagar se os golpes de violência referidos por Lazzarato não teriam sido precedidos por golpes microfísicos justamente para preparar, desde o cotidiano, as subjetividades para aceitarem a violência da imposição em curso. A pergunta de Foucault, nesse plano, é crucial: “o que é que permite a emergência, como é que isso se fez?" (FOUCAULT, 2004 a, p. 15).

Se, como visto, o neoliberalismo é um modo de ser e de pensar, reinvenção constante visando a generalizar em todo o corpo social a lógica das trocas monetárias, Foucault (2004 a) destaca dois processos necessários para a consolidação de tal perspectiva. Ambos processos envolvem diretamente a formação subjetiva. Eles são: os sujeitos considerados como capital humano e os sujeitos reduzidos à relação competência-máquina.

O capital humano ocupa lugar de destaque no modo de pensar do neoliberalismo (BECKER, 1993; FRIEDMAN, 1955; SCHULTZ, 1961). Esse aspecto foi ressaltado também por Foucault (2004 a), para quem o capital humano passou a ser possibilidade de reinterpretar em termos estritamente econômicos a dimensão subjetiva. Para Foucault, é o investimento em si mesmo, ou seja, o sujeito fazendo de sua subjetividade a matéria prima de seu autoempreendedorismo a marca do capital humano. 
O cúmulo do capital humano é a precarização, no sentido em que os sujeitos do neoliberalismo se veem abandonados sobre si mesmos, dependentes por completo das condições de seus territórios existenciais. Desse ponto de vista, o capital humano é a primeira exploração que o neoliberalismo introduz no dispositivo de segurança. No limite, o entendimento do fracasso econômico de cada sujeito é jogado na autorresponsabilização do sujeito, por não ter investido o suficiente em sua autoformação subjetiva, logo, transformando-se em um sujeito desatualizado para si mesmo.

Para Schultz (1961), o capital humano é um produto deliberado do investimento do sujeito sobre si mesmo. As tensões ao redor do autoempreendedorismo passam, então, a ser condizentes com tal perspectiva (ANTUNES, 2018; HOSANG; LOWDENS, 2019), pois o capital humano é a introdução vertiginosa aos componentes de adaptabilidade às demandas humanas neoliberais. Schultz (1961, p. 1) apresenta as propaladas "habilidades e conhecimentos" como fontes do capital humano, mas também Becker (1993), Friedman (1955), o ideário neoliberal da BNCC (2018) respaldado pela veridicção neoliberal do PISA/OCDE (2018).

O ponto de convergência do capital humano para o neoliberalismo é a adaptabilidade inconteste. Sob tal rubrica, conhecimento e habilidade são potências subjetivas que precisam ser consideradas como “investimentos críticos variáveis, determinantes na variação do crescimento econômico em sua relevância e importância" (SCHULTZ, 1961, p. 7). Ora, são investimentos críticos variáveis senão as formas pelas quais os sujeitos passam por processos educativos constantes visando às suas adequações à variação do crescimento econômico. Não é à toa que Friedman (1955, s/p) considera que o papel da educação, em termos globais, é o de fornecer valores mínimos comuns e um grau mínimo de conhecimento para que os sujeitos compreendam seus devidos papéis na governança: "preservar as regras nos jogos de contrato, protegendo da coerção, e manter o livre mercado"

O capital humano é um saque teórico e empírico às potências subjetivas que são impedidas de não se sacrificarem, desde a autoexploração, à própria exploração do capitalismo. Nesse caso, e para piorar, o capital humano é imprescindível para que a "educação crie formas de consumo de capital" (SCHULTZ, 1961, p. 12). Assim, quando o mesmo Schultz (1961, p. 11) argumenta que, para analisar os efeitos do capital humano nos ganhos na educação, "é preciso distinguir o estoque da educação na população e o montante da força de trabalho", um dos efeitos perversos do dispositivo de segurança do neoliberalismo se revela, a saber. Na medida que grande parte da população tem acesso à educação e o nível de trabalho não coincide com a educação atingida, será necessário intervir no capital humano para preparar seus sujeitos a aceitarem condições sub-humanas e precárias de "força de trabalho".

Em outro nível, a adequação da competência-máquina, como mostrou Foucault (2004 a, p. 229), passa a integrar a vitalidade do capital humano no sentido de ser uma "programação estratégica da atividade dos indivíduos". Se Foucault (2004, p. 230) sintetiza o capital como "tudo que pode ser de uma maneira ou 
de outra fonte de ganhos futuros", a competência-máquina assinala para uma economia realizada ao custo da imanente culpabilização do sujeito: ser ou não ser competente como fonte de ganhos futuros que, por extensão, é dependente de quanto cada sujeito investiu sobre si mesmo como capital humano. Daí o sentido da valorosa passagem de Foucault (2004 a, p. 230):

A atitude para trabalhar, a competência, o poder-fazer alguma coisa, tudo isso não pode ser separado daquilo que é a competência e daquilo que se pode fazer. Dito de outro modo, a competência do trabalhador é uma máquina, mas é uma máquina que não se pode separar do próprio trabalhador [...]. É preciso considerar que a competência que faz corpo com o trabalhador é, de algum modo, o lado pelo qual o trabalhador é uma máquina, mas uma máquina entendida no sentido positivo, pois é uma máquina que vai produzir fluxos de ganhos.

O ponto nodal é da seguinte ordem: o capital humano é a dimensão teórica que atua na produção empírica do modo de ser da competência-máquina de cada um. A associação de ambos indica o ponto de mutação do capitalismo dentro dos circuitos de veridicção neoliberal, cuja força extrema implica na mutação subjetiva para que os comportamentos sejam fluxos de adequação programada, sempre conforme os circuitos estabelecidos de competências que precisam ser ativadas. Nada mais óbvio, porque "educação e formação (education and training) são os mais importantes investimentos em capital humano"(BECKER, 1993) e porque "desnacionalizar a educação" - leia-se, privatizá-la - "poderia aumentar o espectro de escolha dos pais"(FRIEDMAN, 1955, s/p), ou seja, poderia melhor destinar a elite para continuar sendo elite enquanto os precarizados seriam meros lacaios daqueles.

O neoliberalismo como componente majoritário do dispositivo de segurança contemporâneo amplia os tentáculos de como a subjetividade é, concomitantemente, produzida e preparada para servir como máquina-competência à sua arte de governar. Desde aí, o neoliberalismo ativa

numerosos programas, propostas e políticas que têm tentado moldar a conduta de indivíduos - não somente controlar, subjugar, disciplinar, normalizar ou reformálos, mas também torná-los mais inteligentes, sábios, felizes, virtuosos, saudáveis, produtivos, dóceis, empreendedores, satisfeitos, cheios de autoestima, dotados de poder, ou o que quer que seja (ROSE, 2001, p. 25).

O paradoxo se dá apenas entre inputs e outputs das competências: os ricos continuarão onde estão e os pobres jogados para a ponta do precariado, explorado por aqueles. Eis a promessa da liberdade de escolha neoliberal reduzida às possiblidades forçadas da veridicção da adaptabilidade. Ser livre é ser adaptável aos conhecimentos, às competências, às atitudes, às habilidades e aos valores infligidos como verdade a ser assumida e protagonizada egoicamente. A essa altura pesam os diagnósticos de Laval (2019, p. 39): 
O que está em jogo é o enfraquecimento de tudo que serve de contrapeso ao poder do capital e tudo que institucionalmente, juridicamente e culturalmente limita sua expansão social. Todas as instituições, além da economia, foram afetadas por essa mutação, inclusive a instituição da subjetividade humana: o neoliberalismo visa a eliminação de toda "rigidez", inclusive psíquica, em nome da adaptação às situações mais variadas com o que o indivíduo depara no trabalho e na vida.

Todo esse horizonte desemboca no fetiche da aprendizagem ao longo da vida, cujo leitmotiv faz do mínimo capital humano acumulado pela passagem escolar, a potência necessária à adaptação urgente. Portanto, sob tal viés, "o life long learning prepararia menos para um 'diploma', o qual daria acesso a um emprego e a uma carreira, para 'competências básicas comercializáveis' (marketable skills), as quais permitiriam a constante adaptação do assalariado às transformações econômicas e às necessidades do mercado" (LAVAL, 2019, p. 72). A partir do momento que as necessidades do mercado puxam para a ponta do precariado a maior parte dos habitantes da terra (ANTUNES; 2018; HOSANG; LOWDENS, 2019; STANDING, 2017), as competências básicas comercializáveis também precisam se adequarem à formação ininterrupta de uma subjetividade que, ao mesmo tempo, precariza-se.

As políticas globais assumem a dianteira na guerra da veridicção neoliberal, criando, por variáveis discursivas e estratégias empíricas de intervenção nas políticas públicas de educação, considerável papel decisivo de influência, como analiso doravante. Mas para tanto, a subjetividade do precariado precisa ser justificada a partir de uma guerra fractal, nos termos de Alliez e Lazzarato (2016), cujo espaço de atuação é a própria política neoliberal como arte de governar.

\section{Subjetividades precárias: incidências na escola pública brasileira}

Faço do diagnóstico de Laval (2019; p. 9) o mesmo: "atribuo à introdução do neoliberalismo uma grande responsabilidade da degradação mundial das condições de vida e de trabalho". A degradação não se refere apenas ao aumento exponencial da vulnerabilidade das condições materiais de subsistência ${ }^{\text {iv }}$, mas também aos condicionantes subjetivos que determinam a permanência dos sujeitos na precariedade. Não se pode ignorar o fato de que a demanda da relação capital humano com a adaptabilidade ao mercado igualmente pressiona, de modo perverso, o papel da educação pública na precarização, inclusive pelo fato de os Estados Nacionais permitirem grosso modo a sua precarização, no lugar de defendê-la. Mas o que é a precarização e o seu corolário, o precarizado?

Em primeiro lugar, a precarização é um efeito dos modos de ser e de pensar da arte de governar neoliberal, considerando o fato de que "as elites abandonaram seus compromissos com proteção econômica, suportes institucionais e programas de redistribuição de renda" (HOSANG; LOWNDES, 2019; 58) tão fundamentais na mitigação das desigualdades econômicas. O motivador é a exacerbação dos lucros 
irresponsáveis que, sob a plataforma do dispositivo de segurança, devem ser protegidos de todas as maneiras. O plano de toda austeridade econômica neoliberal encontra-se naquela conjuntura, e nos termos de $\mathrm{Hu}$ (2020), austeridade não combina com solidariedade.

A extensão da precarização como efeito, contudo, gera outros efeitos que passam a ser, paradoxalmente, motivadores de sua própria causa. É que os sujeitos lançados à precarização, por padecerem da guerra fractal do neoliberalismo contra o Estado, sendo destituídos de sua rede de proteção social e, então, verem-se abandonados exclusivamente à sua frágil competência-máquina, reproduzirão o ciclo incansável da precarização.

Assim, essa difícil classe de ser definida, sob os argumentos de Standing (2017), emerge como sombrio sintoma, espécie de efeito colateral da produção de riquezas. O precariado reflete, pois, a precarização delineada e condizente com a aceleração das fragmentações dos apoios solidários e comunitários, catalisados pela deterioração de relações sociais pautadas na confiança mútua. Conforme argumenta Standing (2017, p. 30),

o precariado não é o nível de salários em dinheiro ou de rendas auferidas em qualquer momento específico, mas a falta de apoio da comunidade em momentos de necessidade, a falta de benefícios assegurados da empresa ou do Estado e a falta de benefícios privados para completar ganhos em dinheiro.

É possível ver nesses termos o papel que a assunção do capital humano desempenha, já que no neoliberalismo o sucesso individual passa a ser parâmetro da autossuficiência de cada um. Por derivação, cada qual é objeto a ser vencido no lastro da competição pela sobrevivência atomizada onde, o que conta, é o privatismo subjetivo da competência, da habilidade e do capital humano de cada um.

Por isso mesmo, a competência-máquina tem de ser extorquida diariamente sob uma insana demanda de adaptação furtiva. Como um vaga-lume, o que hoje brilha em sua utilidade sob medida, amanhã poderá se extinguir, pois não há nada que garanta a sua necessidade aos interesses majoritários de uma política econômica regida pelo rentismo. As consequências podem ser percebidas na análise impecável de Standing (2017, p. 48):

O precariado não é uma classe organizada que busca ativamente seus interesses, em parte porque está em guerra consigo mesmo. Um grupo dentro dele pode responsabilizar outro por sua vulnerabilidade e indignidade. Um trabalhador temporário com baixo salário pode ser induzido a ver o "parasita de benefícios sociais' como alguém que obtém mais, de forma injusta e às suas custas. As tensões dentro do precariado estão colocando as pessoas umas contra as outras, impedindoas de reconhecer que a estrutura social e econômica está produzindo seu conjunto comum de vulnerabilidades. Muitos serão atraídos por políticos populistas e mensagens neofascistas. 
Perniciosas perspectivas se abrem sob tal conjuntura. Na farta pesquisa de Hosang e Lowndes (2019), confirma-se que a plutocracia neoliberal se empenha em qualificar os que necessitam da intervenção do Estado, quer seja para a proteção de seus direitos trabalhistas ou apoio de rede social de proteção, de parasitas, preguiçosos, exploradores de trabalhadores honestos, vagabundos, malandros e comunistas. No entanto, ela reserva para si mesma a alcunha de produtiva e patriota, a classe que defende os interesses de seu país. O precariado passa a aceitar a sua condição com receio de ser associado aos inimigos do produtivismo neoliberal.

Isso também é um dos motivos do precariado ser uma classe difusa e em guerra consigo mesma. $\mathrm{O}$ fato de o neoliberalismo ser agente de defesa do dispositivo de segurança, reforça constantemente processos de identificação associados à necessidade imediata de cada sujeito defender a sua própria condição existencial. A flutuação dos trabalhos temporários, flexíveis, sem vínculos de estabilidade, subordinados às sazonalidades e altamente rotativos compõem a tessitura do referido dispositivo. O impacto subjetivo é o da seguinte ordem: adaptar-se ao precariado para não ser classificado pelos processos identitários e perversos como parasita social.

Nessa órbita, o dispositivo de segurança lança mão do racismo de Estado imediatamente. É que a associação dos resistentes à precarização com a parasitagem conecta-os imediatamente à inferiorização existencial, porém, atrelada aos condicionantes raciais, tal como Foucault analisou (1999, 2002; 2004 b). Consequentemente, “o discurso racial demoniza a provisão pública, a regulação e a redistribuição das riquezas, além de promover formas mais severas de vigilância, repressão e encarceração" (HOSANG; LONWDES, 2019, p. 150). O neoliberalismo potencializa perversamente formas de segregação temporárias que não deixam de incidir em algumas permanentes. Nessa direção, Melamed (2006) comprova como, por exemplo, ser homem, branco, heterossexual, conservador, já indicia vantagem no precariado, enquanto ser mulher ou negro, homossexual, engajado em movimentos sociais progressistas passa a ser uma desvantagem.

Não se pode, portanto, desconsiderar que o precariado vocaliza o racismo de Estado como técnica de governamentalidade neoliberal, desempenhando, concomitantemente, um papel importante nos operadores de corte fundamentais entre vida e morte: "O que inseriu o racismo nos mecanismos do Estado foi a emergência desse biopoder. [...] O corte entre o que deve viver e o que deve morrer", precisa Foucault (2002, p. 304).

Em suma, a precarização apresenta-se como tecnologia de poder imprescindível à arte de governar neoliberal. Efeito e causa de si mesma, condiciona o precariado à manutenção de suas tecnologias de poder. Municiado com a veridicção do capital humano e da competência-máquina, o neoliberalismo transborda a face perversa do racismo: viver dependerá da intensidade com que cada sujeito se submete às verdades políticas neoliberais. O passo decisivo nas estratégias de planejar, organizar e difundir a precarização 
encontra-se, a seguir, nas intervenções neoliberais de precarização da escola pública. Afinal de contas, é desde cedo que se deve educar a potência subjetiva para a adaptação e a adequação mercantil.

Foucault (2004 a, p. 235) argumenta que, no neoliberalismo, "os investimentos educativos" encontram-se na encruzilhada do capital humano e da competência-máquina, pois tais investimentos transcendem a especificidade da aprendizagem escolar. Está sendo dito que, desde o tempo dispensado pelos pais com atenção aos seus filhos, os estímulos culturais recebidos, as condições dispensadas aos cuidados com a saúde - alimentação correta, segurança sanitária, sono adequado etc. - ativam-se investimentos educativos que impactam no capital humano e nas distintas competências-máquinas.

A partir desse diagnóstico, pode-se sustentar que precarizar a escola pública faz parte da racionalização veridiccional neoliberal. Quer dizer, quanto mais bem aparelhada com as materialidades técnicas e tecnológicas, culturais, sociais, dotada de espaços adequados e não populosos, com professores longe da precarização, da sobrecarga de trabalho, dentre outros aspectos, maior é a capacidade da escola impactar no capital humano e na consistência subjetiva de cada um. Mas o contrário também é verdadeiro. Assim, precarizar a escola é fundamental para assegurar que seus sujeitos sejam introduzidos ao investimento inicial de precarização ao longo da existência. A defesa da privatização da educação e do esvaziamento do papel do Estado se situam na junção perfeita na manutenção das desigualdades e injustiças sociais.

Por conseguinte, argumenta Standing (2017, p. 110),

o Estado neoliberal vem transformando os sistemas escolares para torná-los uma parte consistente da sociedade de mercado, pressionando a educação na direção da formação de "capital humano" e da preparação para o trabalho. Isso tem sido um dos mais indecorosos aspectos da globalização.

Tal análise ganha maior vigor quando alguns dados são trazidos como pano de fundo da arte de governar neoliberal. Ao se investigar com cautela a proposta que a Organização para a Cooperação e o Desenvolvimento Econômico (OCDE, 2018) aporta com o PISA, salta aos olhos um tríplice destaque. Primeiro, a educação objetiva as competências fundamentais a ser planificadas no âmbito global. A demanda predominante para tal argumentação abrange as necessidades do mercado. Segundo, as competências fundamentais extrapolam componentes curriculares formais e dizem respeito a uma formação indireta de capital humano adequado às necessidades do mercado. Terceiro, não há uma linha sequer considerando a falência do mercado, aportado na arte de governo neoliberal. Em outros termos, a função da educação é preparar seus sujeitos para a entrada em um mundo tenebroso de desigualdade social, de desafios, de multicultura, de exigências à criatividade, de demanda à sociabilidade passiva, meramente respeitosa e não transformadora dos avatares de sua injustiça produzida economicamente. 
Para a OCDE (2018, p. 15, grifos meus), o PISA é um instrumento fundamental para equalizar as demandas globais dessa educação cuja "competência global exige numerosas habilidades, incluindo saber raciocinar com informação, com habilidades comunicativas em contextos interculturais, com tomadas de perspectiva, habilidades em resolução de conflitos e adaptabilidade". No final, a chave-mestra é essa: tudo se converge para a adaptabilidade. Os termos de Laval (2019, p. 125) sintetizam toda conveniência em jogo: a escola, doravante, deve "se adaptar ao mercado generalizado, porque esse é o estado natural da sociedade, e não resistir, como se esperaria de uma escola pública”.

Assim, a OCDE (2018, p. 13) busca entabular quatro competências básicas e indissociáveis que, por sua vez, são indissociáveis para a perfeita adaptação dos sujeitos à inquestionável ordem: "foco na correlação e interdependência entre sociedades e economias". Claro está, tal interdependência não pode ser tensionada, colocada à prova ou submetida ao crivo de sua limitação.

Sinteticamente (OCDE, 2018, p. 11), em primeiro lugar, o conhecimento é capturado como competência destinada a "entender e a apreciar a perspectiva e a cosmovisão dos outros". Em segundo lugar, encontram-se os valores: competência que permite o "engajamento aberto, apropriado e efetivo na interação entre culturas". A próxima competência concerne às atitudes, isto é, saber "agir para o bem-estar da coletividade e o desenvolvimento sustentável. Finalmente, a quarta competência diz respeito às habilidades: "examinar problemas interculturais locais e globais". O quadro abaixo demonstra a articulação das competências.

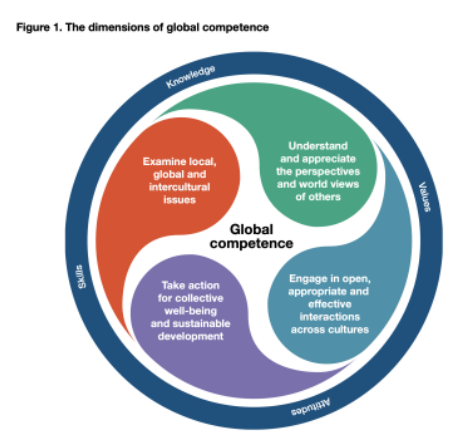

Chama a atenção de como os verbos supõem uma passividade equidistante: "entender", "apreciar", "engajar-se abertamente", "examinar". Sem tintura, a estrutura das competências se volta menos para uma formação e mais para uma formatação subjetiva. Nem o aspecto do agir para o "desenvolvimento sustentável" se salva, pois está condicionado à tomada de ação para e pelo "coletivo". Para se ter ideia do impacto que isso representa, o termo "transformação" aparece apenas uma vez no documento, mas para constatar as transformações digitais e as suas influências na sociedade contemporânea. Enquanto isso, "adaptação" e "adaptabilidade" pipocam por dez vezes no documento, destacando, inclusive, o que é “adaptabilidade" (OCDE, 2018, p. 15): 
Adaptabilidade refere-se à capacidade de adaptar os pensamentos e comportamentos ao ambiente cultural predominante ou a novas situações e contextos que podem apresentar novas demandas ou desafios. Os indivíduos que adquirem essa habilidade são capazes de lidar com os sentimentos de "choque cultural", como frustração, estresse e alienação em situações ambíguas causadas por novos ambientes. Os alunos adaptáveis podem desenvolver mais facilmente relacionamentos interpessoais de longo prazo com pessoas de outras culturas e permanecer resilientes às mudanças das circunstâncias.

Os termos são autoexplicativos. Também é autoexplicativo porque "neoliberalismo" não aparece no documento. $\mathrm{O}$ destaque à adaptabilidade diz tudo, afinal de conta, não é o neoliberalismo, para se usar os termos adequados da OCDE, o "ambiente cultura predominante"? Não é o neoliberalismo contemporâneo esse moedor humano que se impõe como Novo Mundo, espécie de "nova situação e contexto que pode apresentar novas demandas ou desafios"? E não é para isso que precisamos de "alunos adaptáveis", capazes de se relacionar, sobretudo, sendo "resilientes às mudanças das circunstâncias"? E os sujeitos não precisam ser formados a partir deste, justamente para se adaptarem à "frustração, estresse e alienação em situações ambíguas causadas por novos ambientes”, tais como os decorrentes da precarização?

É preciso uma boa dose de irrealidade para não enxergar a desidratação dos investimentos públicos para a escola o agente terceirizador do Estado pelo neoliberalismo. Ao cabo, trata-se de refundar o pacto formativo ao redor das subjetividades precárias. A adaptabilidade é ensinada precocemente. Assim Laval (2019, p. 299) lança luz no argumento:

Essa grande mutação da escola não é fruto da racionalidade dos especialistas ou resultado da exigência democrática de transparência. Sua principal razão de ser são os imperativos de produtividade impostos cada vez mais insistentemente a uma organização produtora de capital humano. Desse ponto de vista, os valores em concorrência que fundamentavam o sentido social da cultura e da escola não têm mais razão de ser. Do ponto de vista da instância suprema que é o mercado, apenas o valor dos produtos da organização escolar tem sentido hoje.

Ora, as competências incensadas na Base Nacional Comum Curricular (BRASIL, 2018) e consideradas a coluna cervical do documento normativo a definir o conjunto de "aprendizagens essenciais" de todos os alunos no decorrer das etapas e das modalidades da Educação Básica, ecoam a veridicção neoliberal para a educação. No singular, competência repete-se 79 vezes e, no plural, 71. Praticamente se testemunha um vício de linguagem, tão necessário aos processos de lavagem cerebral. A BNCC (BRASIL, 2018, p. 8) replica no espelho neoliberal, a plataforma global para a educação sintetizada pela OCDE:

competência é definida como a mobilização de conhecimentos (conceitos e procedimentos), habilidades (práticas, cognitivas e socioemocionais), atitudes e valores para resolver demandas complexas da vida cotidiana, do pleno exercício da cidadania e do mundo do trabalho. 
É claro, entretanto, que "resolver demandas complexas da vida cotidiana" apenas quer dizer saber adaptar-se ao mundo do trabalho que se impõe. Ou não é de se causar estranheza que em um documento com fôlego pretensioso, 595 páginas, não haja nenhuma menção ao neoliberalismo e apenas 2 menções à economia, sendo uma delas mera epígrafe e a outra menção às "economias criativas", essas, sim, tão importantes à adaptação?

Há de se dizer que a BNCC, depois de tantas revisões, acabou sendo promulgada no apagar das luzes do Governo de Michel Temer. Também é curioso notar o declínio dos investimentos públicos na educação brasileira, desde então. Extraídos da nota técnica do DIEESE (2019 a, p. 10), abordando os Desafios da Educação Brasileira: comentários sobre os indicadores da publicação Education at a Glance 2019 - OCDE, os dados abaixo são estarrecedores:

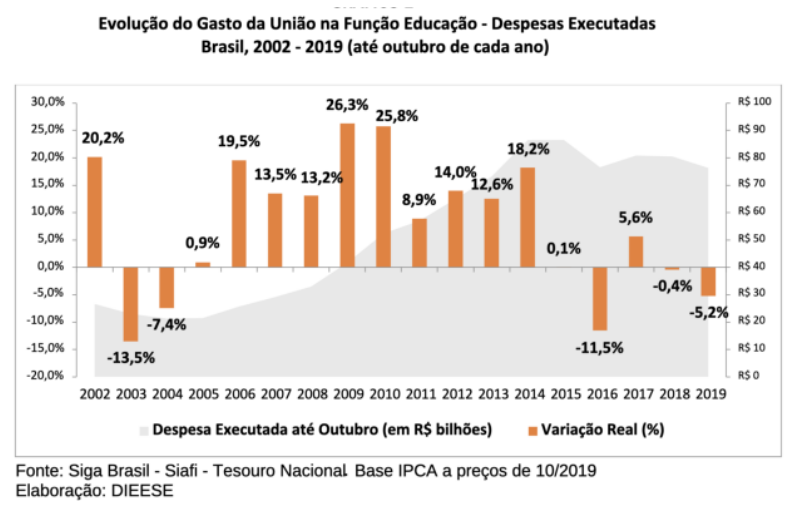

Após 10 consecutivos anos de investimentos positivos do Governo Federal, a partir de 2016, há uma retração incansável. $\mathrm{O}$ argumento poderia ser a crise econômica, mas aquela que sucedeu à crise de 2008 não impactou negativamente nas despesas executadas. É claro que a entrada hipertrofiada do neoliberalismo no Estado brasileiro impactou diretamente nos dados. Tanto é, que o Ministério da Educação atual, isto é, a partir de 2019, milita contra o investimento público na educação, justamente por considerar que o Brasil investe quase 6\% de seu PIB na Função Educação (FÁVERO, 2019), índice superior ao de muitos países da OCDE.

Datavenia, é verdade que o montante bruto investido supera o de muitos países da OCDE, mas esquece-se da peculiar realidade desigual, distorcida e carente no âmbito continental brasileiro. Essa desconsideração condiz com o racismo de Estado neoliberal, ou seja, viabilizar a normalização da entrada na precarização e, ademais, não interferir nas condições materiais que pudessem mitigar a injustiça no corte social entre o que deve viver e o que deve morrer.

Apesar disso, os dados revelam outra dimensão. Quando se leva em consideração a relação investimento por aluno, o Brasil se desponta como um dos últimos (BRASIL, 2019, p. 18), bem próximo do nível da Colômbia. 


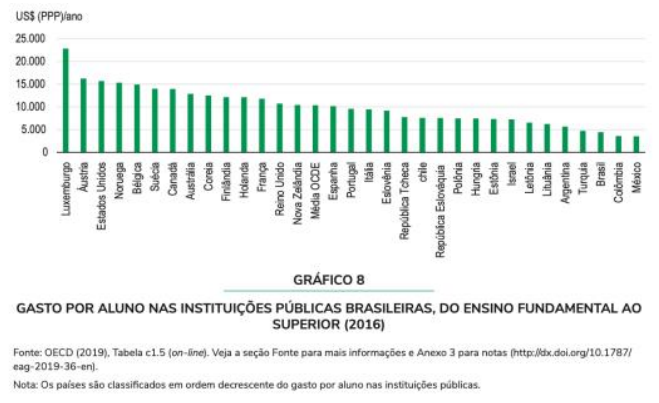

As dimensões continentais do país, somadas à profunda desigualdade social e a pobreza acentuada, diluem o montante bruto dos investimentos na educação. Evidencia-se também que os recursos não são suficientes para que a escola pública penetre com equanimidade na profunda malha social brasileira. Levando em consideração dados recentes, estima-se que a população brasileira experimenta o avanço da pobreza:

Por exemplo, de 2016 para 2017, houve crescimento da pobreza segundo os três critérios de "linha de pobreza" utilizados pelo IBGE para identificar pessoas pobres. Na linha de pobreza mais elevada, de cerca de $\mathrm{R} \$ 406,00$ como rendimento mensal domiciliar per capita, a proporção de pobres passou de 25,7\%, em 2016, para 26,5\% da população brasileira em 2017 (DIEESE, 2019 b, p. 2)

Esses dados lançam luz a um impasse de grande impacto. Considerando os dados revelados pelo INEP (BRASIL, 2019, p. 19), os investimentos na educação básica, por aluno, nas instituições públicas brasileiras é em torno de US\$3,800.00, menos da metade da média dos países da OCDE (US\$ 9,300.00). A disparidade é gritante. Ao considerar que o ensino médio é gargalo ainda insolúvel no cumprimento do ciclo final da educação básica dos jovens no Brasil, constata-se, possivelmente, o encontro perverso de duas situações. De um lado uma escola longe de ser aparelhada com condições materiais ideais e atualizadas, "mais doente do estado da sociedade" (JOSHUA, 2000, p. 15), ou seja, precarizada e incapaz de propor à juventude uma contrapartida de experiências situacionais fora do esquadro da precarização. De outro lado, essa "pobre escola como escola para os pobres", na afiada percepção de Joshua (2000, p. 19), é mantida assim, quiçá, em decorrência do número de jovens compelidos ao trabalho precoce, incertos no círculo vicioso da precarização familiar e, portanto, reforçando o abandono escolar

Quando Standing (2017) diagnostica que a juventude constitui o núcleo do precariado, há de se atentar para a frustração de status que acomete a juventude brasileira. Ainda que os jovens queiram estudar, a precarização pressiona-os, cada vez mais, para fora da escola. Por sua vez, o Estado parasitado pelo neoliberalismo passa a operar um decréscimo de investimento, pois, no final das contas - e são contas, literalmente - o aluno destinado à precarização, de modo forçoso, cumprirá o seu papel, independentemente da escola. 
Assim, o Brasil detém taxas perversas que impactam diretamente na precarização da juventude: o alto número de jovens fora da escola e um índice apequenado de jovens que chegam a concluir o ensino médio (DIEESE, 2019, p. 6).

\begin{tabular}{|c|c|c|}
\hline Etapas de ensino & População & Proporção (em \%) \\
\hline Ensino médio & 6.255 .098 & 63 \\
\hline Ensino fundamental & 2.341 .810 & 24 \\
\hline Concluiu o ensino médio & 145.614 & 1 \\
\hline Fora da escola & 1.182 .145 & 12 \\
\hline Total & 9.924 .668 & 100 \\
\hline
\end{tabular}

Soma-se a isso o fato de o Brasil possuir a segunda maior taxa de desempregados na população jovem de 18 a 24 anos, a reboque dos que se encontram fora da escola, atrás apenas da Grécia (14\%), conforme dados do INEP (BRASIL, 2019, p. 11):

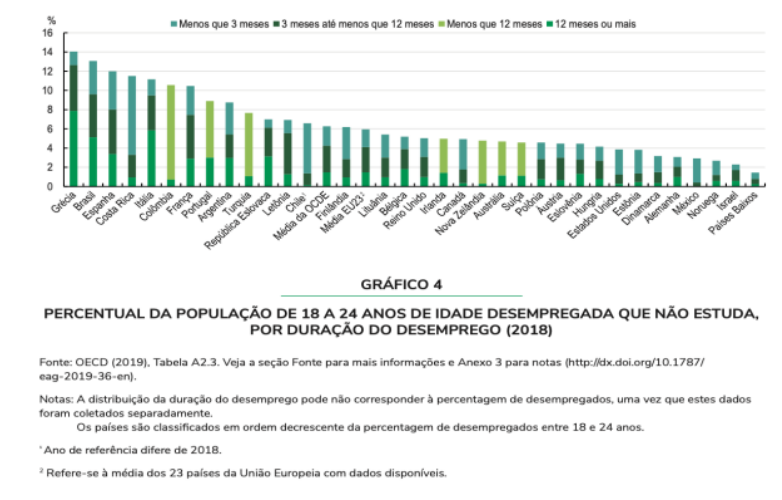

A quem convém, portanto, a narrativa de que os investimentos são mais do que suficientes para a educação pública no Brasil? Convém à mesma plutocracia que lucra com a precarização, enquanto seus filhos estudam em escolas muito bem equipadas, destinados a liderarem a veridicção neoliberal. Convém ao empresariado e ao agronegócio brasileiro. Para as empresas que migram para regiões profundas do Brasil, a mão de obra precarizada é grande negócio, ao mesmo tempo consubstanciada numa subjetividade cada vez mais afastada da solidariedade social dos sindicados, das agremiações de trabalhadores, das lutas coletivas etc. Para o agronegócio, a mão-de-obra deve refundar o ciclo perverso da colônia, longe de qualquer direito e reivindicação; condicionada à sazonalidade da demanda e submetida ao jugo do valor ofertado unilateralmente. Mas também convém à supressão elitista de um princípio de realidade brutal: a existência de um Brasil rural; a existência de um Brasil periférico, dentro de suas metrópoles cosmopolitas; a existência de um Brasil que, ao precarizar a escola pública, privilegia o papel da educação privada elitista.

A precarização da escola pública brasileira tornou-se coincidente etapa entre o modo de pensar e o modo de ser neoliberal. Seguindo a hipótese do artigo, trata-se de fazer dela um ritual de iniciação que prepara para a precarização existencial. Defender a escola pública implica numa luta constante contra a sua precarização. Tal luta também se destina a recusar os roteiros veridiccionais que reduzem a potência 
subjetiva a uma plataforma programada de competências funcionais e adaptativas ao neoliberalismo. Ao cabo que, a função da escola é educar para aquilo que a BNCC não ousou afirmar, ou seja, para a ação política de resistência, não modelar, questionadora, limitadora e transformadora às seguintes ordens:

cada vez mais os empregadores procuram atrair alunos que se adaptam facilmente e são capazes de aplicar e transferir suas habilidades e conhecimentos para novos contextos. A prontidão para o trabalho em um mundo interconectado exige que os jovens compreendam a dinâmica complexa da globalização" (OCDE, 2018, p. 5. Grifos meus)

Mas agora já se sabe: precarizar a escola pública é condicioná-la à demanda de precarização existencial. E isso, já não podemos aceitar nem consentir.

\section{Considerações finais: defender a escola do precariado é defender a escola pública}

É bem possível que a precarização tenha longo alcance histórico, talvez enquanto a arte de governar neoliberal persistir com suas veridicções e sua política de defesa da sociedade tal qual seus dispositivos de segurança engendram.

Nesse diagnóstico, a escola pública padece das mesmas forças que atuam no neoliberalismo. A sua precariedade, como foi explorado, é pertinente ao dispositivo de segurança, pois bloquear a qualidade da escola pública é fortalecer a ponta da educação das elites. Foi mostrado que são elas os cães de guarda do neoliberalismo, ao passo que parasitam o Estado, terceirizando-o conforme suas conveniências.

Para não repetir essa vulgata, a escola pública tem de ser defendia de modo pleno, institucional e deslocada dos interesses preconizados, como aferiu Foucault (2004 a), dos modos de pensar e de ser neoliberais. Cumpre lembrar, nesse plano, que "o saber não gera nenhuma autonomia e independência se não recusa o "quadro" dentro do qual funciona, se não interrompe, se não detém a produção, de que não constitui mais que uma peça" (LAZZARATO, 2019, p. 161). A escola pública não pode se reduzir a uma peça do rolo compressor neoliberal.

Para tanto, a escola pública é desafiada a não se distanciar do seu papel intercessor de situar os seus sujeitos na multiplicidade do pensamento, na diferença existencial, na razão contestatória, nos princípios da contradição do pensamento, na democracia dos credos, dos sexos, das cores, das culturas, porém, não para aceitá-las passivamente, mas para produzi-las constantemente. As demandas impositivas por competências afinadas ao capital humano e à subjetividade reduzida a simples competência-máquina, inclusive capaz de afetar as políticas públicas brasileiras, como a BNCC, não podem continuar sendo desculpa para arrimar a precarização da formação humana, nesse caso, destilando a destruição criativa da singularidade de cada espaço escolar. A experiência com educação deve estar longe da reprodução dos 


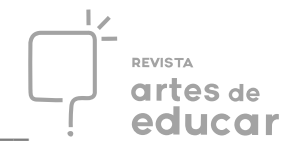

parâmetros da racionalidade, calculabilidade, eficiência e previsibilidade padronizadas pelas competências, como se tratasse de "Mcdonaldizar" a formação humana e a escola Ritzer (2000).

É preciso agir a favor dos investimentos econômicos na escola pública. Isso é tão urgente quanto refundar os processos políticos voltados para a superação das injustiças sociais impregnadas no tecido social brasileiro. Por isso mesmo, a escola pública precisa ser uma contraprova dos condicionamentos neoliberais, ou seja, incluir nas experiências formativas coeficientes de ousadia, de solidariedade social, de partilha de espaço, de engajamento com a transformação social, de inadequação à normalização adaptativa. É verdade que

na era neoliberal, a escola visa a formação do assalariado ou, de modo mais geral, do "ativo" cuja existência parece se reduzir à aplicação dos conhecimentos operacionais no exercício de uma profissão especializada ou de uma atividade considerada socialmente útil. Não tendo como perspectiva nada além do campo das profissões e das atividades existentes, ela fecha o homem em um presente ao qual ele deve se adaptar custe o que custar, excluindo a utopia de uma libertação (LAVAL, 2019, p. 65).

Mas há outra verdade. A escola pode ser um ensaio aberto contra a arte de governo neoliberal. E como ensaio aberto, ela permite invocar experimentos na perspectiva de "atividades e posturas, cujas finalidades implicam em distanciar as experiências educativas dos claustros fundamentalistas que circunscrevem a subjetividade humana ao esteio dos limites das verdades que pretendem refletir e reproduzir o mesmo" (CARVALHO, 2014, p. 139). O controle das competências encontra-se no sentido de bloquear qualquer ensaio na Escola. O neoliberalismo, por ser controlador, sabe muito bem disso. Ele sabe que “o sujeito imprevisto implica um 'ato imprevisto', uma ruptura que cria os possíveis de sua própria liberação" (LAZZARATO, 2019, p. 191).

Se "a experiência de uma existência precarizada de uma geração também transmitirá atitudes e normas de comportamentos para a próxima" (STANDING, 2017, p. 109), será apenas intervindo imediatamente contra a precarização das subjetividades preparadas na escola pública precarizada que tal ciclo poderá ser quebrado. E que as vozes opositoras ao neoliberalismo "não sejam temidas, degradadas ou rejeitadas, mas valorizadas pelo incentivo a uma democracia sensata que elas ocasionalmente performam" (BUTLER, 2019, p. 182).

\section{Referências}

ALLIEZ, Éric; LAZZATO, Maurizio. Wars and capitalism. South Pasadena: Semiotext(e), 2016.

ANTUNES, Ricardo. O privilégio da servidão: o novo proletariado de serviços na era digital. São Paulo: Boitempo, 2018. 
BECKER, Gary S. Human Capital. A Theoretical and Empirical Analysis, with Special Reference to Education. Chicago \& London: The University of Chicago Press, 1984.

BERARDI, Franco. A fábrica da infelicidade. Trabalho cognitivo e crise da new economy. Porto Alegre: DP\&A, 2005.

BRASIL. Ministério da Educação. BNCC - Base Nacional Comum Curricular. Brasília: Ministério da Educação, $2018 . \quad$ Disponível em: 〈http://basenacionalcomum.mec.gov.br/images/BNCC_EI_EF_110518_versaofinal_site.pdf $>$. Acesso em: 20 abr. 2020.

BRASIL. Instituto Nacional de Estudos e Pesquisas Educacionais Anísio Teixeira. Panorama da educação. Destaques do Education at a glance 2019. Brasília: Instituto Nacional de Estudos e Pesquisas Educacionais Anísio Teixeira, 2019.

BROWN, Wendy. Nas ruínas do neoliberalismo: a ascensão da política antidemocrática na Ocidente. São Paulo: Politeia, 2019.

BUTLER, Judith. Vida Precária. Os poderes do luto e da violência. Belo Horizonte: Autêntica, 2019.

CARVALHO, Alexandre Filordi de. Foucault e a função-educador. Ijuí: Editora Unijuí, 2014.

CARVALHO, Alexandre Filordi de; GALLO, Silvio Donizete de Oliveira. Lutas democráticas contra o Urstaat: o que pode fazer a educação? In. Revista ETD. Luto é Verbo. Educação e Democracia. v. 21, n. 3, 2019.

DIEESE. Desafios da Educação Brasileira: comentários sobre os indicadores da publicação Education at a Glance 2019. São Paulo, 2019, nov. 2019 a. (Nota técnica 217). Disponível em: < https://www.dieese.org.br/notatecnica/2019/notaTec217educacao.html >. Acesso em 28 abr. 2020.

DIEESE. A importância da política de valorização do salário mínimo e a urgência de renová-la. São Paulo, 2019, nov. 2019 b. (Nota técnica 205). Disponível em: < https://www.dieese.org.br/notatecnica/2019/notaTec205SalarioMinimo.html>. Acesso em 25 abr. 2020.

FÁVERO, Bruno. O que é fato no que disse o ministro da Educação em audiência na Câmara. In. aosfatos.org. 17 mai. 2019. Disponível em: < https://aosfatos.org/noticias/o-que-e-fato-no-que-disse-oministro-da-educacao-em-audiencia-na-camara/> Acesso em: 26 abr. 2020.

FOUCAULT, Michel. A vontade de saber. História da sexualidade I. Rio de Janeiro: Graal, 1999.

FOUCAULT, Michel. Em defesa da sociedade. São Paulo: Martins Fontes, 2002.

FOUCAULT, Michel. Naissance da la biopolithique. Paris: Gallimard/Seuil, 2004 a.

FOUCAULT, Michel. Securité, Territoire, Population. Paris: Gallimar/Seuil, 2004 b.

FRIEDMAN, Milton. The Role of Government in Education. In. SOLO, Robert A. Economics and the Public Interest, Trustees of Rutgers College in New Jersey, 1955.

HOSANG, Daniel M.; LOWDNS, Joseph E. Producers, parasites, patriotes. Race and the new right-wing politics of precarity. London/Minneapolis: University of Minnesota Press, 2019.

HU, Zöe. A New Age of Destructive Austerity After the Coronavirus. In. The New Republican. Abr. 23 mai. 2020. Disponível em: < https://newrepublic.com/article/157417/new-age-destructive-austeritycoronavirus $>$. Consulta em: 23 mai. 2020.

JOHSUA, Samuel. L'école entre crise e refondation. Paris: La Dispute, 2000.

KINZER, Stephen. Overthrow. America's century of regime change. From Hawaii to Iraq. New York: Times Book, 2006. 
KLEIN, Naomi. The shock doctrine. The rise of disaster capitalism. New York: Picador, 2007.

LAVAL, Crhistian. A escola não é uma empresa. O neoliberalismo em ataque ao ensino público. São Paulo: Boitempo, 2019,

LAZZARATO, Maurizio. Gouverner par la dette. Paris: Les Prairies Ordinaires, 2014.

LAZZARATO, Maurizio. Fascismo ou revolução? O neoliberalismo em chave estratégica. São Paulo: N$1,2019$.

LEVITSKY, Steven; ZIBLATT, Daniel. Como as democracias morrem. Rio de Janeiro: Zahar, 2018.

MARTINS, Cristiano Zanin; MARTINS, Valeska. Lawfare: uma introdução. São Paulo: ContraCorrente, 2019.

MAYER, Jane. Dark Money. The hidden history of the billionaires behind the rise of the radical right. New York: Anchor Book, 2017.

MELAMED, Jodi. The Spirit of Neoliberalism: From racial liberalism to Neoliberal multiculturalismo. Social Text 89, Vol. 24, No. 4, 2006, Winter. Disponível em: https://analepsis.files.wordpress.com/2017/01/neolibmulticulti.pdf

OECD. PISA. Preparing our youth for an inclusive and sustainable world. The OECD PISA global competence framework. Organization for Economic Co-operation and development - OECD: 2018. Disponível em: https://www.oecd.org/pisa/Handbook-PISA-2018-Global-Competence.pdf

RITZER, George. The Macdonaldization thesis. London/New Delhi: SAGE Publications, 2000.

ROSE, NIKOLAS. Inventando nossos selfs. Psicologia, poder e subjetividade. Petrópolis: Vozes, 2011.

SCHULTZ, Theodore W. Investiment in humain capital. In. The American Economic Review. V. LI, N. 1, 1961.

STANDING, Guy. O precariado. A nova classe perigosa. Belo Horizonte: Autêntica, 2017, 2017.

STEGER, Manfred; RAVI Roy. Neoliberalism: a very short introduction. New York: Oxford, 2010.

VON MISES, Ludwig. Ação humana - um tratado de economia. São Paulo: Instituto Ludwig von Mises Brasil, 2010. Versão e-book. https://www.mises.org.br/Ebook.aspx?id=44

Recebido em: 30/04/2020.

Aceito em: 03/08/2020.

Notas

\footnotetext{
${ }^{\text {i }}$ Professor no Departamento de Educação da Universidade Federal de Lavras (UFLA) e do Programa de Pós-Graduação em Educação da Universidade Federal de São Paulo (UNIFESP). E-mail: afilordi@gmail.com São Paulo. ORCID: https://orcid.org/0000-0003-4510-9440

ii Os leitores especializados sabem que tal expressão se refere ao curso homônimo de Michel Foucault, ministrado no Collège de France entre 1975-176. Mas não se pode é esquecer que Em defesa da sociedade, conforme sustento, inaugura o circuito das pesquisas de Foucault acerca do dispositivo de segurança.

iii Indica-se a obra de Lawfare: uma introdução (Martins; Martins, 2019) para aprofundamento na questão, sobretudo consoante ao contexto da Java-Jato no Brasil, sua relação direta com a desestabilidade de garantias constitucionais, legais etc dentro da democracia brasileira e a emersão da extrema-direita.
} 
iv Com relação à pobreza os dados não são claros. Enquanto o Banco Mundial considera extremamente pobres indivíduos sobrevivendo com menos de U\$ 1,90 por dia e pobres com menos de U\$ 3.20 por dia (Cf. https://www.worldbank.org/en/topic/poverty/overview), o World Poverty Clock (cf. https://worldpoverty.io) demonstra o inoperância de um ciclo perverso, ou seja, um entra e sai imediato da extrema vulnerabilidade por segundo, com mais 600 milhões de indivíduos na extrema pobreza. Seja como for, o fato é que U\$ 3.20 por dia retira teoricamente o indivíduo da linha de pobreza, mas não do precariado, onde a maior parte dos indivíduos do planeta se encontram, conforme Standing (2017). 